\title{
Optimal Design Methodology on Compensation Parameters of Inductive Power Transfer Converter for Electric Vehicles
}

\author{
Cheol-Hee Jo (D) and Dong-Hee Kim *D \\ Department of Electrical Engineering, Chonnam National University, 77, Yongbong-ro, Buk-gu, \\ Gwangju 61186, Korea; 197597@jnu.ac.kr \\ * Correspondence: kimdonghee@jnu.ac.kr; Tel.: +82-62-530-1736
}

Citation: Jo, C.-H.; Kim, D.-H. Optimal Design Methodology on Compensation Parameters of Inductive Power Transfer Converter for Electric Vehicles. Energies 2021, 14, 8269. https://doi.org/10.3390/ en14248269

Academic Editor: Antonio Cano-Ortega

Received: 1 November 2021 Accepted: 6 December 2021 Published: 8 December 2021

Publisher's Note: MDPI stays neutral with regard to jurisdictional claims in published maps and institutional affiliations.

Copyright: (c) 2021 by the authors. Licensee MDPI, Basel, Switzerland. This article is an open access article distributed under the terms and conditions of the Creative Commons Attribution (CC BY) license (https:/ / creativecommons.org/licenses/by/ $4.0 /)$.

\begin{abstract}
Compensation topologies of the inductive power transfer (IPT) converter for electric vehicles (EVs) have been researched in previous works. However, a methodology for designing a compensation topology based on the efficiency of the IPT converter has been barely discussed. This paper proposes an optimal design methodology for compensation parameters to achieve optimal efficiency of the IPT converter with LCC-S. The optimal output voltage is derived using the losses analysis of the IPT converter, and the IPT converter is designed for the optimal output voltage to achieve the optimal efficiency. Furthermore, the battery management (BM) converter on the receiving side is designed based on the output voltage of the IPT converter, the fluctuation range of the coupling coefficient, and the battery charging voltage. The validity of the proposed IPT converter design methodology is verified by designing different compensation parameters and BM converters. The power rating of the three design cases is $3.3 \mathrm{~kW}$ with the same magnetic pads satisfying the SAE J2954 WPT 1 class.
\end{abstract}

Keywords: battery management (BM) converter; compensation parameter design; efficiency optimization; inductance and double capacitances series (LCC-S); loss analysis

\section{Introduction}

Nowadays, global warming caused by greenhouse gases is becoming a serious problem in the world [1]. Therefore, electric vehicles (EVs) are receiving great attention for environmental protection, energy efficiency, and reducing our carbon footprint. Wireless power transfer (WPT) technology is being developed for charging EVs because it offers many benefits such as convenience, reliability, safety, and lack of mechanical wear compared to conventional wired charging [2-4]. In addition to EV charging, WPT technology has been widely employed for high-power vehicles (e.g., trains and automated guided vehicles) and low-power devices (e.g., implantable devices and consumer electronics) [5].

Although the WPT, also called inductive power transfer (IPT), employs the same principle as a conventional wired charging system using a transformer, a coupling coefficient $(k)$ of a loosely coupled transformer (LCT) is very low in the WPT system for EVs and it varies depending on the location of the receiver [6]. To cope with these problems, research topics include the optimal design of the LCT to achieve a high coupling coefficient and misalignment tolerance $[7,8]$, compensation topologies with constant output current/voltage and zero phase angle (ZPA) characteristics [9], and control methods to regulate the battery charging voltage [10]. Among them, compensation topology can significantly minimize the volt-ampere (VA) rating of the WPT system, improve the power-transfer capability, and help achieve high efficiencies [11].

The main research objective of the compensation topology is to minimize the voltampere rating of the system and to make a constant output voltage/current. The most basic compensation topology is series-series (SS), series-parallel (SP), parallel-series (PS), and parallel-parallel (PP), which are mature and complete [12]. Among them, SS topology is widely employed because it can provide the constant output current regardless of the load 
and achieve the ZPA characteristics [12]. For these reasons, various control methods in the IPT converter with SS topology have been studied to improve the efficiency or regulate the battery charging voltage $[13,14]$. However, the output characteristic of the basic compensation topology, determined by the LCT parameters, might be limited in EVs because of fixed geometric specifications of the coil and magnetic pads by the SAE J2954 standard [15]. Additionally, the basic compensation topologies are vulnerable to the bifurcation phenomenon which makes two or more resonant frequencies depending on the variations in the load and coupling coefficient [12]. Therefore, high-order compensation topologies have been studied to improve the performance of the basic compensation topologies.

Hou et al. [16] presented the impedance conditions and output current characteristics of different current fed compensation topologies; they analyzed and compared the sensitivities of the output current to parameter variation. Lu et al. [17] analyzed the resonant conditions of all voltage-fed compensation topologies in a WPT system to achieve a constant-voltage (CV) output and investigated the parameters' impact on the key performance factors of these composite topologies. Zhang et al. [18] presented a comprehensive review of existing compensation topologies for the loosely coupled transformer and analyzed how to combine resonant blocks to generate any type of compensation topology, guaranteeing the IPT circuit that achieves a constant output and a minimum input voltage-ampere rating simultaneously. Li et al. [19] first proposed a double-sided LCC compensation network and its tuning method; they analyzed the parameter design method to achieve constant output current and zero voltage switching conditions. As seen above, the high-order compensation topologies provide a greater design degree of freedom compared to the basic compensation topology as the required output current/voltage can be designed regardless of the parameter LCT. Among them, the LCC configuration is among the popular compensation networks for resonant converters [20]. This is because the LCC compensation topology on the primary side has the character that the current of the primary coil is not affected by load and mutual inductance. It is more stable and secure than other topologies when there is a large misalignment between primary and secondary coils [21]. Because of these advantages, DS-LCC and LCC-S compensation topologies are widely adopted among high-order compensation topologies for IPT converters [22,23]. The LCC-S compensation topology has a constant output voltage unlike the DS-LCC compensation topology, which has a constant output current regardless of load, so it is preferred for battery charging [24]. In addition, the LCC-S compensation topology can be applied to various applications as well as EVs since it has a simple structure on the receiver side.

The conventional design methodology for compensation parameters of LCC-S compensation topology as well as other high-order compensation topologies for EVs focuses on designing the required output voltage while minimizing the volt-ampere rating of the system and achieving the zero-voltage switching condition [22,23]. Kim et al. [25] proposed a design and control scheme of the inductive power transfer (IPT) system with LCC-S compensation topology for EVs, considering a wide variation in battery charging voltage and coupling coefficient. The required output voltage is selected in consideration of the variation range of the coupling coefficient and the voltage stress of the $\mathrm{dc} / \mathrm{dc}$ converter as called the battery management $(\mathrm{BM})$ converter employed to regulate the battery charging voltage [25]. However, the efficiency of the IPT converter, which has the largest proportion of the overall IPT system, is not considered. Generally, the IPT converter with LCT and compensation topology is the most important part of the WPT system as it generates a significant effect on the power transfer efficiency. Hao et al. [26] proposed an optimized LCC-S compensation topology to have a more robust power characteristic against variation of coupling coefficient. The output voltage ripple remains low despite coupling coefficient fluctuations. However, in stationary charging applications such as EVs, the charging power, not the coupling coefficient, fluctuates continuously during the charging time. Therefore, an optimal design methodology on the compensation parameters of the IPT converter is required in consideration of the main operating point. 
In this paper, an optimal design methodology on the LCC-S compensation parameters of an IPT converter is proposed considering the IPT converter efficiency. To derive the optimal compensation parameters, the losses of the IPT converter are analyzed and compared according to the output voltage of the IPT converter. Based on the above analysis, the study cases are classified according to the main operating point, and each optimal compensation parameter of the IPT converter is derived and designed to have maximum efficiency at the main operating point of each case. Then, the BM converters of each case are designed with consideration of the output voltage of the IPT converter, the fluctuation range of coupling coefficient, and the battery charging voltage. The validity of the proposed design methodology of the IPT converter is verified by designing different compensation parameters and $\mathrm{BM}$ converters for each case. The power rating of the three design cases is $3.3 \mathrm{~kW}$ with the same magnetic pads satisfying the SAE J2954 WPT 1 class.

\section{Theoretical Analysis}

\subsection{Analysis Outline of the LCC-S Compensation Topology}

The conventional WPT system is composed of a power factor correction (PFC) converter to correct the power, the inductive power transfer (IPT) converter for power transmission from the transmitter system to the receiver system, and the BM converter on the receiver side, which controls the output power based on the SOC, as shown in Figure 1. Among them, the IPT converter with the LCC-S compensation topology can be divided into the transmitter and the receiver systems as shown in Figure 2. Both systems are magnetically coupled by the LCT. The transmitter system is composed of a full bridge inverter (FBI), a compensation circuit, and primary coil of the LCT in the IPT converter. The FBI comprising four MOSFETs $S_{1}-S_{4}$ is utilized to convert the DC-link voltage $U_{\text {DC-Link }}$ to the AC voltage $\boldsymbol{U}_{\mathrm{AB}}$ as shown in Figure 2. In the IPT converter, the fundamental harmonic analysis method is widely used for qualitative analysis because the resonant network can suppress harmonics [11]. The relational expression of $\boldsymbol{U}_{\mathrm{AB}}$ and $U_{\mathrm{DC} \text {-link }}$ can be derived as

$$
U_{\mathrm{AB}}=\frac{4 U_{\mathrm{DC}-\mathrm{link}}}{\pi} \sin (\omega t) \sin \left(\frac{\pi D}{2}\right)
$$

where $D$ is the duty cycle of $\boldsymbol{U}_{\mathrm{AB}}$ in the pulse width modulation control [11]. The LCT comprises transmitter and receiver pads. The transmitter pad has a primary coil and a magnetic pad to transmit energy. The receiver pad has a secondary coil and a magnetic pad to receive energy; $L_{\mathrm{p}}$ and $L_{\mathrm{s}}$ represent the self-inductance values of each coil; and $M$ is defined as the mutual inductance between the two coils. The coupling coefficient of the LCT can be derived using $L_{\mathrm{p}}, L_{\mathrm{s}}$, and $M$ as follows:

$$
k=\frac{M}{\sqrt{L_{\mathrm{p}} L_{\mathrm{s}}}}
$$

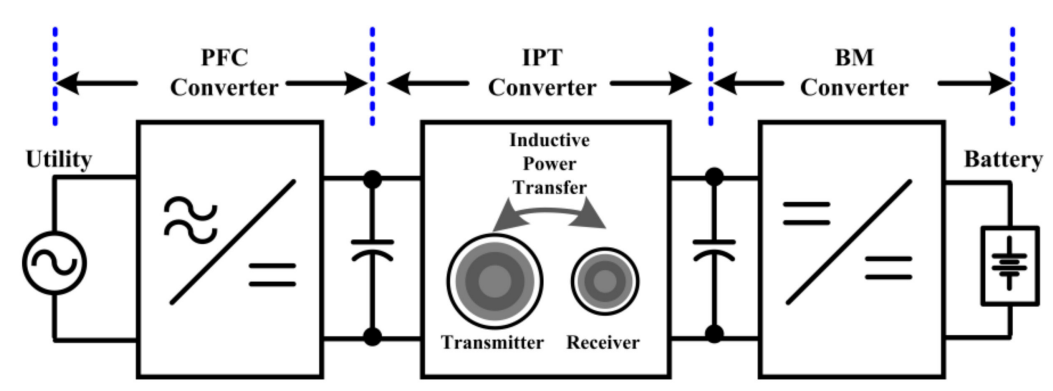

Figure 1. Schematic of the WPT system. 


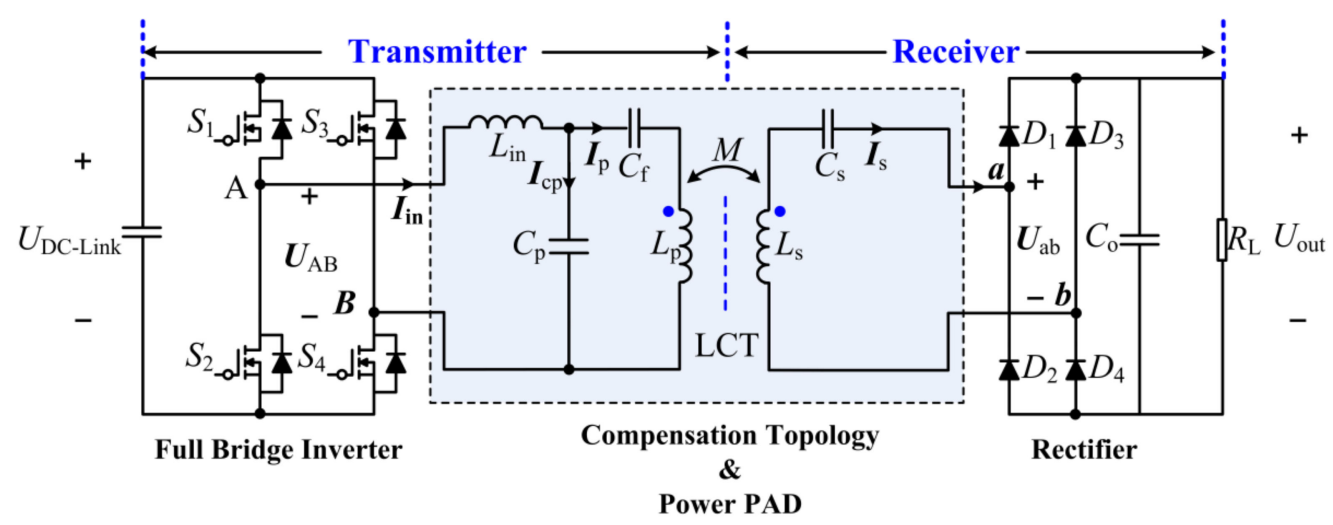

Figure 2. IPT Converter with LCC-S compensated topology.

The receiver system is composed of a secondary coil of the LCT, compensation circuit, and rectifier in the IPT converter. The rectifier is composed of four diodes, $D_{1}-D_{4}$ to rectify the AC output voltage $\boldsymbol{U}_{\mathrm{ab}}$ to the DC output voltage $U_{\text {out }}$ of the IPT converter as shown in Figure 2. The DC output equivalent load and output filter capacitor of the IPT converter are denoted as $R_{L}$ and $C_{0}$, respectively. When the output low-pass filter is made up of a DC capacitor only, the following equation can be deduced [11]:

$$
U_{\text {out }}=\frac{\pi \sqrt{2}}{4} U_{\mathrm{ab}}
$$

where $U_{\mathrm{ab}}$ represents the root mean square (RMS) value of $U_{\mathrm{ab}}$. Additionally, the BM converter is utilized on the receiver side to regulate the battery charging voltage as shown in Figure 1. $R_{L}$ can be expressed as (4) by using the equivalent resistance of the battery $R_{\text {Batt }}$ and the duty $D_{B M}$ of the BM converter based on the buck mode or boost mode of the BM converter. The battery charging voltage $U_{\text {Batt }}$ can be expressed as (5) using the BM converter structure based on the buck mode or the boost mode.

$$
\begin{aligned}
& \begin{cases}R_{L}=\frac{1}{D_{B M}^{2}} R_{\text {Batt }} & \text { (Buck Mode) } \\
R_{L}=\left(1-D_{B M}\right)^{2} R_{\text {Batt }} & \text { (Boost Mode) }\end{cases} \\
& \begin{cases}U_{\text {Batt }}=D_{B M} U_{\text {out }} & \text { (Buck Mode) } \\
U_{\text {Batt }}=\frac{1}{1-D_{B M}} U_{\text {out }} & \text { (Boost Mode) }\end{cases}
\end{aligned}
$$

The LCC-S compensation topology is designed using (6)-(9) based on the input and output voltages of the IPT converter, the resonant frequency, and the LCT parameters of the transmitter and receiver pads, where $U_{\mathrm{AB}}$ and $U_{\mathrm{ab}}$ represent the RMS value of $\boldsymbol{U}_{\mathrm{AB}}$ and $\boldsymbol{U}_{\mathrm{ab}}$, respectively [18]. The input inductor value $L_{\mathrm{in}}$ is determined by the input/output voltage ratio of the IPT converter, and mutual inductance as given in (6). The value of the parallel compensation capacitor $C_{\mathrm{p}}$ is determined to resonate with $L_{\mathrm{in}}$ at the resonant frequency; hence, a constant current is supplied to the primary coil irrespective of the load in an ideal circuit where the parasitic resistance component can be neglected [18]. The value of the primary side series compensation capacitor $C_{\mathrm{f}}$ is designed to achieve no zero-phase angle (ZPA) frequency fluctuation depending on the load. The value of the secondary side series compensation capacitor $C_{\mathrm{s}}$ is determined to resonate with $L_{\mathrm{S}}$ at the resonant frequency for constant output voltage irrespective of the load [18].

$$
\begin{gathered}
L_{\text {in }}=M \frac{U_{\mathrm{DC}-\text { link }}}{U_{\text {out }}} \\
C_{\mathrm{p}}=\frac{1}{\omega^{2} L_{\text {in }}}=\frac{1}{\omega^{2}} \frac{U_{\text {out }}}{M U_{\mathrm{DC}-\text { link }}}
\end{gathered}
$$




$$
\begin{aligned}
C_{\mathrm{f}}=\frac{1}{\omega^{2}} \frac{1}{L_{\mathrm{p}}-L_{\mathrm{in}}} & =\frac{1}{\omega^{2}} \frac{1}{L_{\mathrm{p}}-M \frac{U_{\mathrm{DC}-\text { link }}}{U_{\text {out }}}} \\
C_{\mathrm{s}} & =\frac{1}{\omega^{2} L_{\mathrm{s}}} \\
\boldsymbol{I}_{\mathrm{in}} & =\frac{P_{\text {out }}}{\boldsymbol{U}_{\mathrm{AB}}} \\
\boldsymbol{I}_{\mathrm{cp}}= & \frac{P_{\text {out }}}{\boldsymbol{U}_{\mathrm{AB}}}+j \frac{\boldsymbol{U}_{\mathrm{ab}}}{\omega M} \\
\boldsymbol{I}_{\mathrm{p}} & =\frac{\boldsymbol{U}_{\mathrm{ab}}}{j \omega M} \\
\boldsymbol{I}_{\mathrm{s}} & =\frac{P_{\mathrm{ab}}}{\boldsymbol{U}_{\mathrm{ab}}}
\end{aligned}
$$

The current of each component in the IPT converter can be calculated by (10)-(13). Both the parameter and current equation include $\boldsymbol{U}_{\mathrm{AB}}$ and $\boldsymbol{U}_{\mathrm{ab}}$ as given in (6)-(13). In this paper, the values of the parameters and current (6)-(13) are analyzed using the DC values $U_{\mathrm{DC}-\text { link }}$ and $\boldsymbol{U}_{\text {out }}$ derived as given in (1) and (3) because the AC values $\boldsymbol{U}_{\mathrm{AB}}$ and $\boldsymbol{U}_{\mathrm{ab}}$ are not intuitive for the IPT converter analysis. All of the current magnitudes in the transmitter system are proportional to $U_{\text {out }}$ of the IPT converter except for input current $I_{\text {in }}$, which is proportional to the output power $P_{\text {out }}$ irrespective of $U_{\text {out }}$. In contrast, it can be observed that the current $I_{\mathrm{s}}$ in the receiver is inversely proportional to $U_{\text {out }}$ of the IPT converter. Figure 3 shows the component value and the current magnitude of the LCC-S topology according to $U_{\text {out }}$ based on Table 1 including the measured LCT parameters. Therefore, it is possible to derive the optimal $U_{\text {out }}$ for the IPT converter with the maximum efficiency by analyzing and comparing the losses in the transmitter and receiver systems according to $U_{\text {out }}$ in the IPT converter.

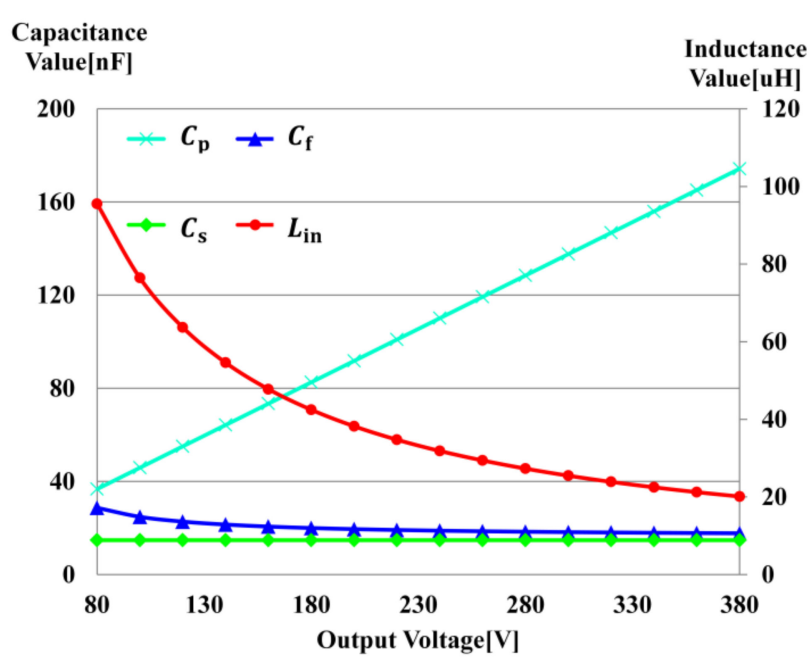

(a)

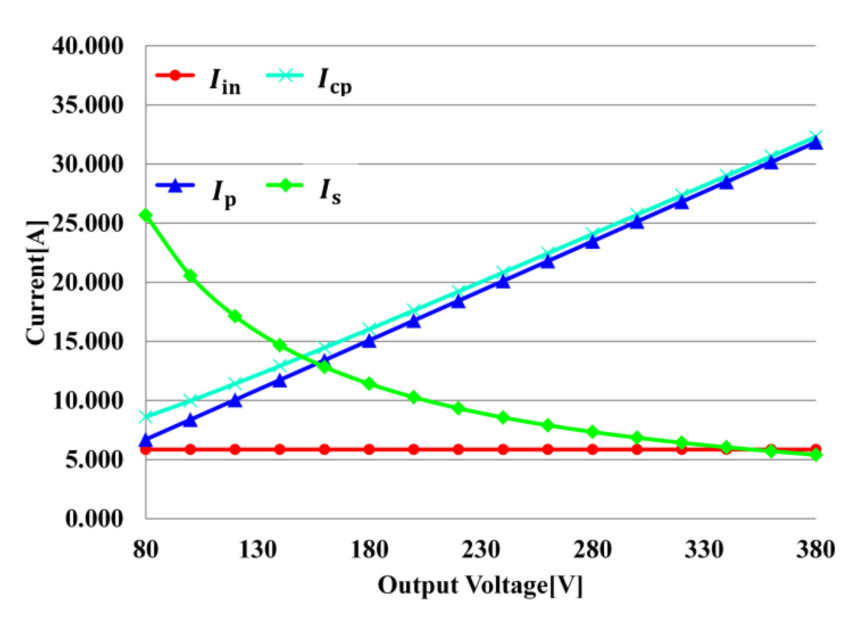

(b)

Figure 3. Component and current of LCC-S topology according to output voltage; (a) component value, (b) magnitude of current. 
Table 1. Electrical specification of the WPT system.

\begin{tabular}{ccc}
\hline Symbols & Parameters & Values \\
\hline$U_{\mathrm{DC}-\text { link }}$ & DC-link input voltage & $380 \mathrm{~V}$ \\
$f_{\mathrm{r}}$ & Resonant frequency & $85 \mathrm{kHz}$ \\
$P_{\mathrm{O}}$ & Output power rating & $3.3 \mathrm{~kW}$ \\
$k$ & Coupling coefficient & 0.08 \\
$L_{\mathrm{p}}$ & Primary coil inductance & $216 \mu \mathrm{H}$ \\
$L_{\mathrm{s}}$ & Secondary coil inductance & $237 \mu \mathrm{H}$ \\
\hline
\end{tabular}

\subsection{Losses Analysis of Power Semiconductor and Compensation Topology}

The FBI losses comprise the conduction, switching, parasitic capacitor, and diode losses. The conduction and switching losses that are proportional to $I_{\text {in }}$ account for the largest proportion of inverter losses. As shown in Figure $3 b, \boldsymbol{I}_{\text {in }}$ is a constant value irrespective of $U_{\text {out }}$ when operating in the ZPA. Therefore, the losses of the inverter are expected to be constant irrespective of $U_{\text {out }}$.

The inductor losses are divided into copper and core losses. For copper loss, there are two losses in the IPT converter operating at high frequency: the skin effect (including DC losses) and the proximity effect. A litz wire is used to minimize both losses. The DC resistance $R_{\mathrm{DC}}$ can be derived as (14) using the diameter $d$, number of strands $n$, length $l$, and conductivity $\sigma$ of the conductor. The skin effect loss $P_{\text {skin }}$ can be derived as (15) using $F_{R}(\mathrm{f})$ which is a function of frequency; it represents the increment of the resistance caused by the skin effect. The proximity effect loss $P_{\text {prox }}$ can be derived as (16) using $G_{R}(f)$, which is also a function of frequency; it represents the increment of the proximity effect, and $\hat{H}$ is the peak value of the external magnetic field [27]. By designing $L_{\text {in }}$ using the same litz wire and core, the resistance of $L_{\text {in }}$ is determined in proportion to the number of turns which is proportional to the inductance of $L_{\mathrm{in}}$. Thus, the copper loss of $L_{\text {in }}$ is proportional to $L_{\text {in }}$ because the value of $I_{\text {in }}$ is constant irrespective of $U_{\text {out }}$.

$$
\begin{gathered}
R_{\mathrm{DC}}=\frac{4 l}{\sigma n \pi d^{2}} \\
P_{\text {skin }}=R_{\mathrm{DC}} \cdot F_{\mathrm{R}}(f) \cdot I_{\text {in }}^{2} \\
P_{\text {prox }}=n \cdot R_{\mathrm{DC}} \cdot G_{\mathrm{R}}(f) \cdot\left(\hat{H}^{2}+\frac{I_{\text {in }}^{2}}{2 \pi^{2} d}\right)
\end{gathered}
$$

For core loss, it can be calculated based on Steinmetz equation as

$$
P_{\text {core }}=k_{\text {core }} f^{\alpha} B_{\text {peak }}^{\beta}
$$

where $k_{\text {core, }} \alpha$, and $\beta$ are provided by the manufacture as the coefficient values of the core, and $B_{\text {peak }}$ is the peak of magnetic flux density. The core loss of $L_{\text {in }}$ is determined in proportion to $B_{\text {peak }}$ which is proportional to the inductance of $L_{\mathrm{in}}$. Thus, the core loss of $L_{\text {in }}$ is also proportional to $L_{\text {in }}$. Therefore, the $L_{\text {in }}$ losses are inversely proportional to $U_{\text {out }}$ because $L_{\text {in }}$ is inversely proportional to $U_{\text {out }}$ as given in (6).

The capacitor loss can be calculated using the dissipation factor (DF), which is the ratio of the reactance component to the equivalent series resistance (ESR). The DF is calculated as follows:

$$
\mathrm{DF}=(\mathrm{ESR}) \times 2 \pi f_{s w} \mathrm{C}
$$

The ESR value of $C_{\mathrm{p}}$ is expected to be inversely proportional to $U_{\text {out }}$ because the capacitance of $C_{\mathrm{p}}$ is proportional to $U_{\mathrm{out}}$ as given in (7). In contrast, the magnitude of $\boldsymbol{I}_{\mathrm{cp}}$ is proportional to $U_{\text {out }}$ as given in (11). Therefore, the loss of $C_{\mathrm{p}}$ is proportional to $U_{\text {out }}$ because the loss is proportional to the square of the current. However, the slope of the loss is expected not to be steep because the ESR is inversely proportional to $U_{\text {out. }}$. The ESR value of the $C_{\mathrm{f}}$ is proportional to $U_{\text {out }}$ because the capacitance of $C_{\mathrm{f}}$ is inversely proportional to 
$U_{\text {out }}$ as given in (8). Additionally, the magnitude of $\boldsymbol{I}_{\mathrm{p}}$ is proportional to $U_{\text {out }}$ as given in (12). Therefore, the loss of $C_{\mathrm{f}}$ is proportional to $U_{\text {out }}$, and it can be expected that the slope of the loss is steep. The capacitance of $C_{\mathrm{s}}$ is always constant irrespective of $U_{\text {out }}$ as given in (9), and $\boldsymbol{I}_{\mathrm{s}}$ is inversely proportional to $U_{\text {out }}$ as given in (13). Thus, the loss of $C_{\mathrm{s}}$ is inversely proportional to $U_{\text {out }}$ unlike the loss of $C_{\mathrm{p}}$ and $C_{\mathrm{f}}$.

The rectifier losses are divided into conduction and reverse recovery losses. However, the reverse recovery loss can be neglected because the Schottky diode is used in this study; only the conduction loss is considered, as follows:

$$
P_{\text {Diode,cond }}=V_{T H} \boldsymbol{I}_{s, \text { avg }}+R_{D} \boldsymbol{I}_{s, r m s}^{2}
$$

where $\boldsymbol{I}_{s, r m s}$ is the rms value of the secondary coil current.

The rectifier loss is inversely proportional to $U_{\text {out }}$ because $I_{\mathrm{S}}$ is inversely proportional to $U_{\text {out }}$. Therefore, the losses of the transmitter and the receiver components in the IPT converter have opposite characteristics based on $U_{\text {out }}$.

\subsection{Loss Analysis of LCT}

The losses of the LCT are divided into copper and core losses. The copper loss of the LCT where a litz wire is used can be derived in the same way as that of $L_{\mathrm{in}}$. From (15) and (16), it can be seen that the copper losses of the primary and secondary coil are proportional to the value of each current. Therefore, the copper loss of the primary coil is proportional to $U_{\text {out }}$. In contrast, the copper loss of the secondary coil is inversely proportional to $U_{\text {out }}$. This is because $I_{\mathrm{p}}$ and $\boldsymbol{I}_{\mathrm{s}}$ have opposite characteristics with respect to $U_{\text {out }}$ as given in (12) and (13).

For core loss of the LCT, although it is difficult to calculate the accurate core loss of the transmitter and receiver pads in the LCT with a large air gap, it is possible to predict the trend by calculating the magnetic flux of each pad. To analyze the magnetic flux of the LCT, it is necessary to simultaneously analyze the transmitter and receiver pads because the LCT is magnetically coupled as shown in Figure 4. The magnetic flux $\boldsymbol{\Phi}_{\mathrm{p}}$ of the transmitter pad can be divided into the primary leakage magnetic flux $\boldsymbol{\Phi}_{\mathrm{p} \text {,leakage }}$ and the mutual magnetic flux $\boldsymbol{\Phi}_{\mathrm{m}}$ combined with the receiver pad as given in (20). The magnetic flux $\boldsymbol{\Phi}_{\mathrm{s}}$ of the receiver pad can be divided into the secondary leakage magnetic flux $\boldsymbol{\Phi}_{\mathrm{s} \text {,leakage }}$ and the mutual magnetic flux $\boldsymbol{\Phi}_{\mathrm{m}}$ combined with the transmitter pad as given in (21). Both $\boldsymbol{\Phi}_{\mathrm{p} \text {,leakage }}$ and $\boldsymbol{\Phi}_{\mathrm{s} \text {, leakage }}$ can be derived using the number of turns, the current of each coil, and the leakage inductance through the transformer model as given in (22) and (23), respectively [11]. In addition, $\boldsymbol{\Phi}_{\mathrm{m}}$ can be obtained using the number of turns, magnetizing current $I_{\mathrm{m}}$, and the magnetizing inductance using the transformer model as given in (24) [11].

$$
\begin{gathered}
\boldsymbol{\Phi}_{\mathrm{p}}=\boldsymbol{\Phi}_{\mathrm{p}, \text { leakage }}+\boldsymbol{\Phi}_{\mathrm{m}} \\
\boldsymbol{\Phi}_{\mathrm{s}}=\boldsymbol{\Phi}_{\mathrm{s}, \text { leakage }}+\boldsymbol{\Phi}_{\mathrm{m}} \\
\boldsymbol{\Phi}_{\mathrm{p}, \text { leakage }}=\frac{L_{\mathrm{p}, \text { leakage }} \boldsymbol{I}_{\mathrm{p}}}{N_{\mathrm{p}}} \\
\boldsymbol{\Phi}_{\mathrm{s}, \text { leakage }}=\frac{L_{\mathrm{s}, \text { leakage }} \boldsymbol{I}_{\mathrm{s}}}{N_{\mathrm{s}}} \\
\boldsymbol{\Phi}_{\mathrm{m}}=\frac{L_{\mathrm{m}} I_{\mathrm{m}}}{N_{\mathrm{p}}}
\end{gathered}
$$




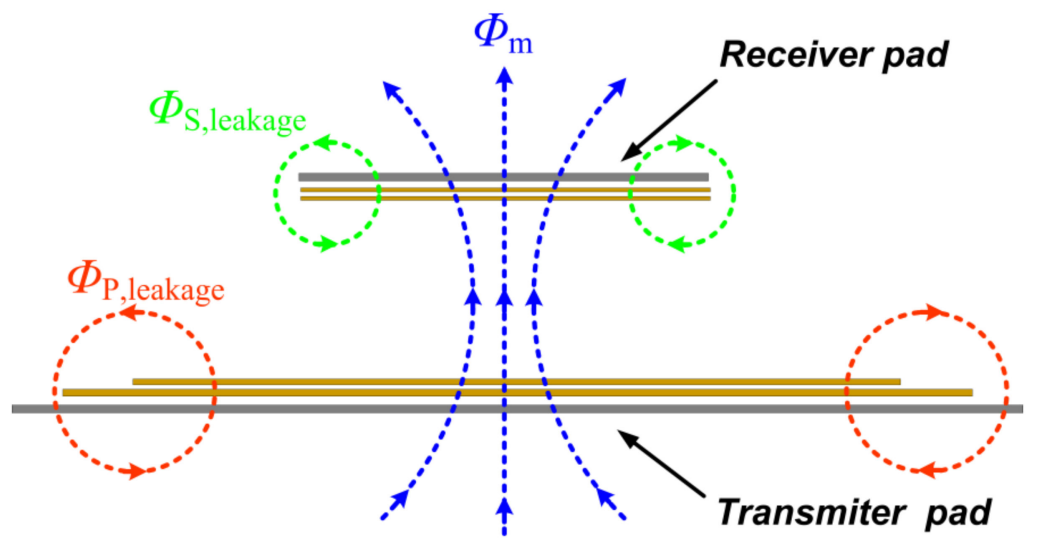

Figure 4. Simplified magnetic flux distribution of pad.

The magnetic flux analysis on the LCT with low $k$ and large leakage inductance should be differently applied from an ideal transformer with high $k$ and small leakage inductance. This is because the ideal transformer has a constant voltage source, whereas the LCT with the LCC-S compensation topology has a constant current source as shown in Figure 5. Therefore, the magnetic flux of the LCT is analyzed according to the load and $U_{\text {out }}$. The magnitude and the phase of $I_{\mathrm{m}}$ are constant in the ideal transformer because the constant voltage source is applied to the load. In contrast, the magnitude and the phase of $\boldsymbol{I}_{\mathrm{m}}$ are changed in the LCT with the LCC-S compensation topology because the magnitude of $\boldsymbol{I}_{\mathrm{S}}$ is changed as per the load based on the constant $\boldsymbol{I}_{\mathrm{p}}$ as shown in Figure 6a. Moreover, $\boldsymbol{\Phi}_{\mathrm{m}}$ is changed as per the load because the magnitude and phase of $\boldsymbol{\Phi}_{\mathrm{m}}$ are determined by $\boldsymbol{I}_{\mathrm{m}}$ as given in (24). In the transmitter pad, $\boldsymbol{\Phi}_{\mathrm{p}, \text { leakage }}$ is constant irrespective of the load because $\boldsymbol{\Phi}_{\mathrm{p} \text {,leakage }}$ is determined by the constant $\boldsymbol{I}_{\mathrm{p}}$ as given in (22). Although $\boldsymbol{\Phi}_{\mathrm{m}}$ is proportional to the load, the variation of $\boldsymbol{\Phi}_{\mathrm{p}}$ which is derived from the vector sum is not significant.

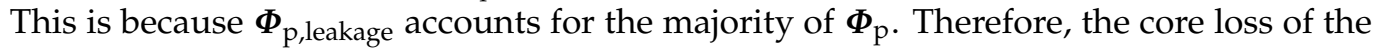
transmitter pad is almost unchanged with the load variation. In the receiver pad, $\Phi_{\text {s,leakage }}$ which accounts for the majority of $\boldsymbol{\Phi}_{\mathrm{s}}$ is changed as per the load in addition to $\boldsymbol{\Phi}_{\mathrm{m}}$ because $\boldsymbol{\Phi}_{\text {s,leakage }}$ is determined by $\boldsymbol{I}_{\mathrm{s}}$. The variation of $\boldsymbol{\Phi}_{\mathrm{s}}$ which is derived using the vector sum is significantly changed according to the load. Therefore, the core loss of the receiver pad is significantly changed based on the load variation, unlike the transmitter pad.

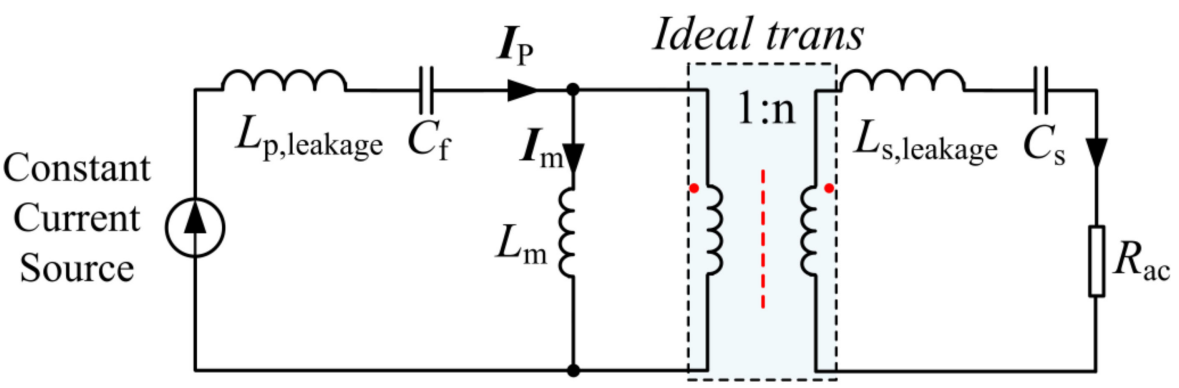

Figure 5. Transformer equivalent model-based analytical circuit of the LCC-S compensation topology. 


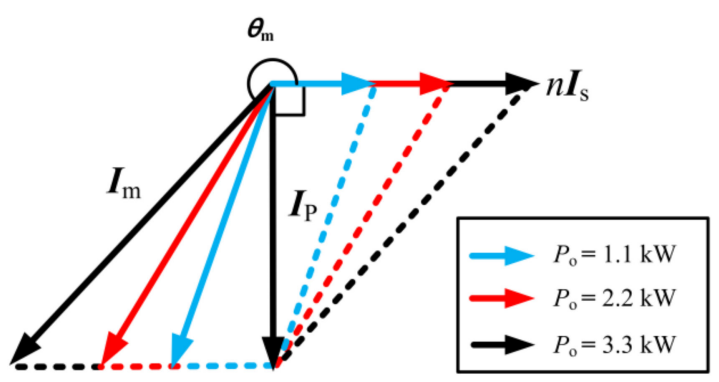

(a)

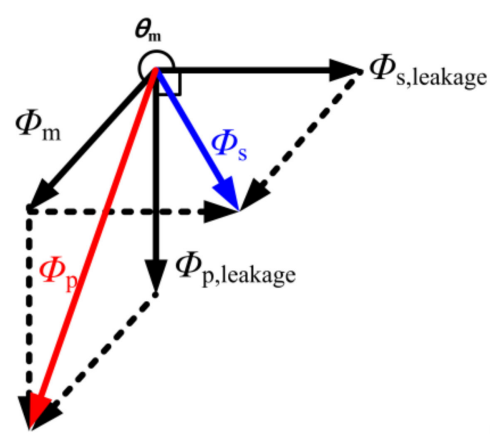

(b)

Figure 6. Phase diagram of the LCC-S compensation topology; (a) coil current, (b) magnetic flux.

The $\boldsymbol{\Phi}_{\mathrm{p} \text {,leakage }}$ and $\boldsymbol{\Phi}_{\mathrm{m}}$ are proportional to $U_{\text {out }}$ because the magnitude of $\boldsymbol{I}_{\mathrm{p}}$ increases in proportion to $U_{\text {out }}$. Therefore, the core loss of the transmitter pad is proportional to $U_{\text {out }}$. In the receiver pad, $\boldsymbol{\Phi}_{\mathrm{s} \text {,leakage }}$ is inversely proportional to $U_{\text {out }}$ because the magnitude of $I_{\mathrm{s}}$ decreases in proportion to $U_{\text {out }}$. Although $\boldsymbol{\Phi}_{\mathrm{m}}$ is proportional to $U_{\text {out }}, \boldsymbol{\Phi}_{\mathrm{s}}$ is inversely

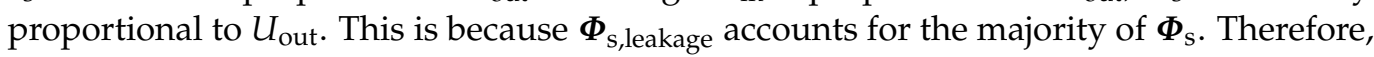
the core loss of the receiver pad is inversely proportional to $U_{\text {out }}$. The copper and core losses of the transmitter pad are almost unchanged according to the load and are proportional to $U_{\text {out }}$. In contrast, the copper and core losses of the receiver pad are changed as the load varies and are inversely proportional to $U_{\text {out }}$.

Figure 7 shows all theoretical component losses of the transmitter and receiver system in the IPT converter with a $3.3 \mathrm{~kW}$ output power. The finite element method simulation is used for accurate core loss calculation. As expected, the $C_{\mathrm{f}}$ and transmitter pad losses account for the largest proportion of the transmitter system loss and exhibit the most sensitive fluctuations based on $U_{\text {out }}$. All component losses in the receiver system fluctuate sensitively with $U_{\text {out }}$. The loss relationship between the transmitter and the receiver system shows a trade-off with $U_{\text {out }}$ in the IPT converter as shown in Figure 7c. Therefore, the optimal output voltage $U_{\text {out,opt }}$ can be selected by the proposed methodology.

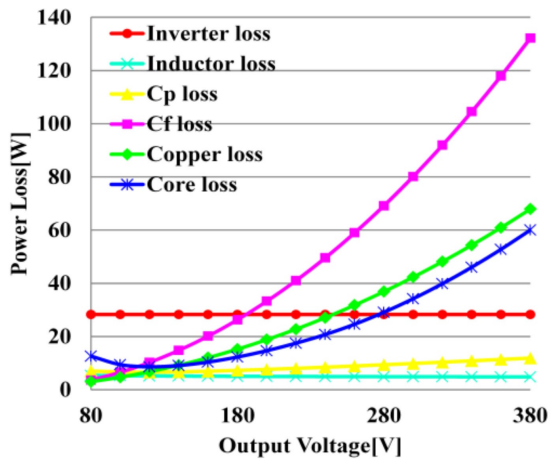

(a)

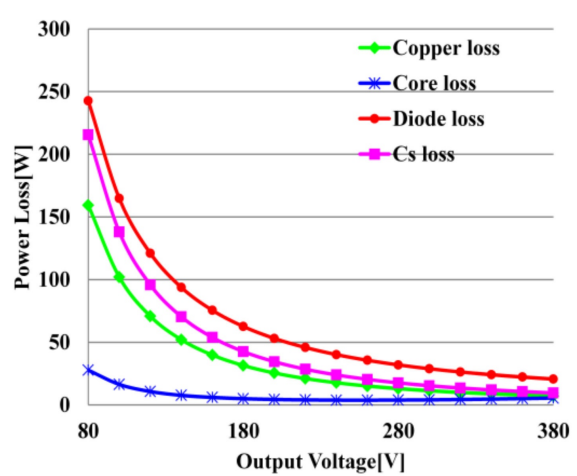

(b)

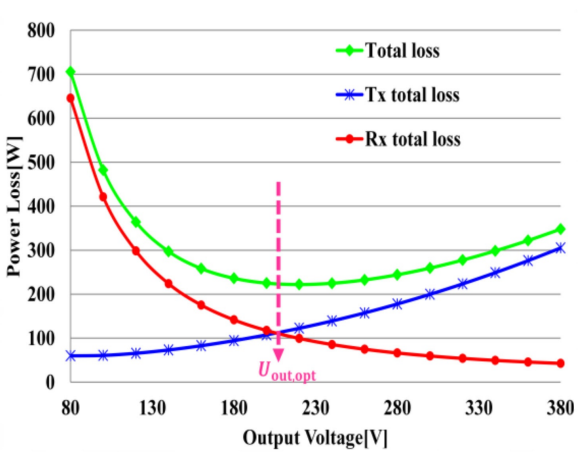

(c)

Figure 7. Theoretical loss of IPT converter according to output voltage; (a) transmitter system, (b) receiver system, (c) total loss at $3.3 \mathrm{~kW}$. 


\section{Optimal Design of IPT Converter Based on the Main Operating Point}

Based on the foregoing analysis, the loss in the $3.3 \mathrm{~kW}$ class IPT converter can be analyzed, and $U_{\text {out,opt }}$ can be derived as given in (25).

$$
\frac{d}{d U_{\text {out }}}\left|P_{\text {loss }, T x}+P_{\text {loss }, R x}\right|_{U_{\text {out }}=U_{\text {out }, \text { opt }}}=0
$$

Furthermore, the BM converter can be designed based on the variation range of $U_{\text {out,opt }}$ according to the fluctuation range of $k$ and $U_{\text {Batt }}$. Therefore, in the proposed methodology, the compensation parameters are designed in consideration of the efficiency of the IPT converter, and the BM converter is designed in consideration of the input/output voltage range. The proposed methodology can increase the design freedom of the IPT converter by considering the characteristics of the transmitter and receiver system, but the rated coil current of the LCT must be taken into account when analyzing the losses of the IPT converter. The proposed design procedure for optimal efficiency is shown in Figure 8. In this section, the case studies are classified, and the compensation parameters of each case are designed by applying the proposed methodology.

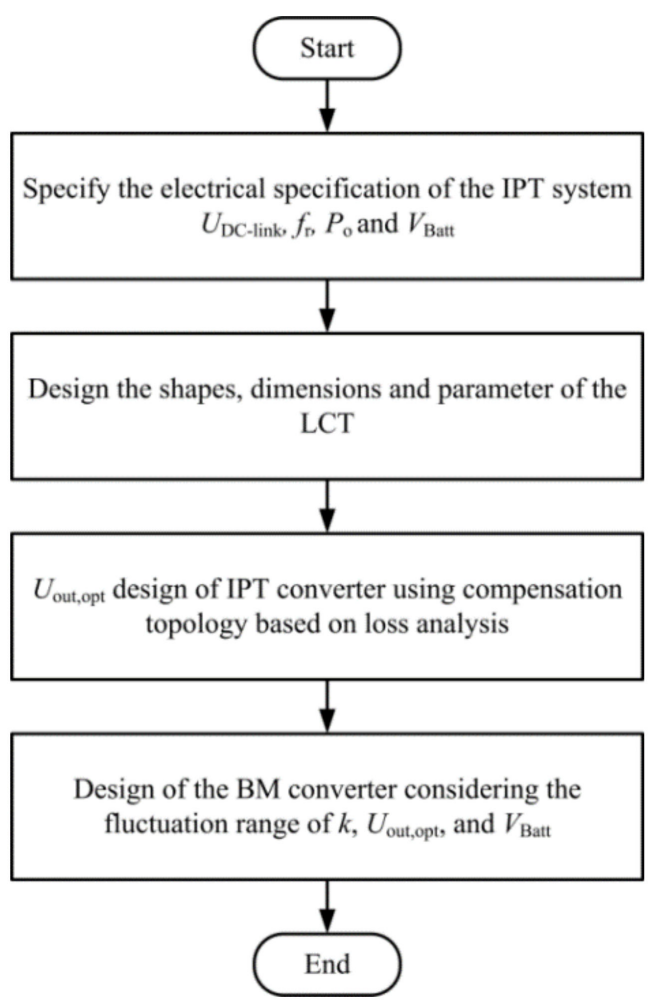

Figure 8. Flowchart of the proposed design procedure of the LCC-S topology for optimal efficiency.

The electrical specifications of the IPT converter are listed in Table 1. Figure 9 shows the manufactured transmitter and receiver pads based on the recommended case of the WPT1 level of SAE J2954 [15]; the LCT parameters and pad dimensions are listed in Table 2. The resistance value of the primary and the secondary coil is calculated by (14)-(16) in consideration of the skin effect and proximity effect. The study cases are classified according to the main operating point and SOC as shown in Figure 10, and the loss in each case is analyzed according to $U_{\text {out }}$ to achieve the maximum efficiency at the main operating point. The main operating points and SOCs of Case 1, Case 2, and Case 3 are $820 \mathrm{~W}$ and $90 \%$ or more, $1435 \mathrm{~W}$ and $80 \%$ or more, and $2800 \mathrm{~W}$ and $50 \%$ or less, respectively, as listed in Table 3; all cases are rated at $3.3 \mathrm{~kW}$. 
Ferrite Magnetic Plates

Coils

Coils

Reiceiver pad

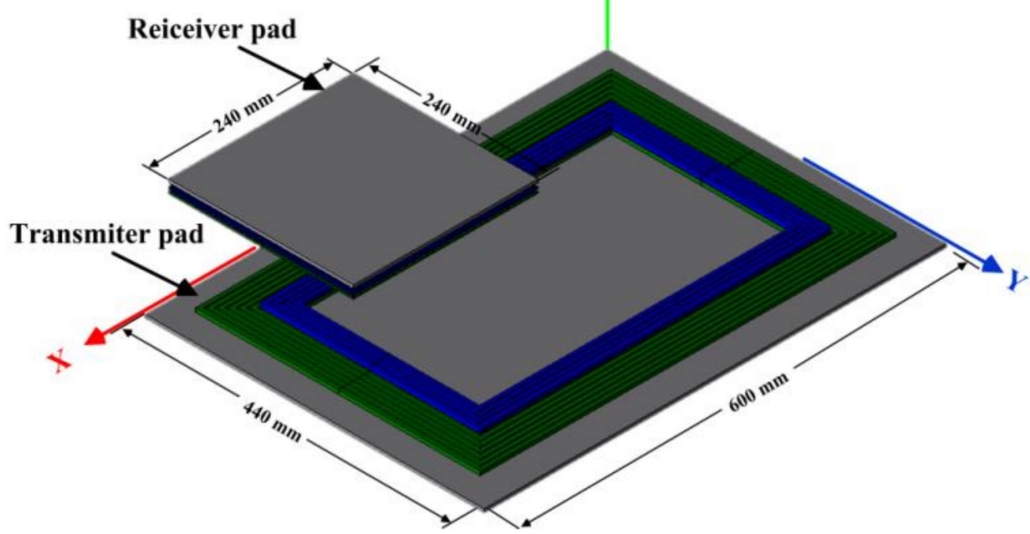

Figure 9. 3D geometric structure and dimensions of the designed LCT.

Table 2. Designed dimensional parameters of the LCT.

\begin{tabular}{cc}
\hline Parameter & Values \\
\hline Vertical distance & $100 \mathrm{~m}$ \\
Horizontal distance & $\pm 150 \mathrm{~mm}(\mathrm{X}), \pm 100 \mathrm{~mm}(\mathrm{Y})$ \\
Turn per coil & $N_{\mathrm{p}}: 14$ \\
Primary coil dimension & $N_{\mathrm{s}}: 22$ \\
Secondary coil dimension & $640 \mathrm{~mm} \times 400 \mathrm{~mm} \times 5 \mathrm{~mm}$ \\
Primary ferrite dimension & $250 \mathrm{~mm} \times 250 \mathrm{~mm} \times 3 \mathrm{~mm}$ \\
Secondary ferrite dimension & $660 \mathrm{~mm} \times 180 \mathrm{~mm} \times 4 \mathrm{~mm}$ \\
& $250 \mathrm{~mm} \times 250 \mathrm{~mm} \times 4 \mathrm{~mm}$ \\
LCT parameters & $L_{\mathrm{p}}=216 \mu \mathrm{H}, L_{\mathrm{s}}=237 \mu \mathrm{H}$ \\
& $k=0.08-0.14$ \\
& $R_{\mathrm{p}, \text { coil }}=54 \mathrm{~m} \Omega, R_{\mathrm{s}, \text { coil }}=93 \mathrm{~m} \Omega$ \\
\hline
\end{tabular}

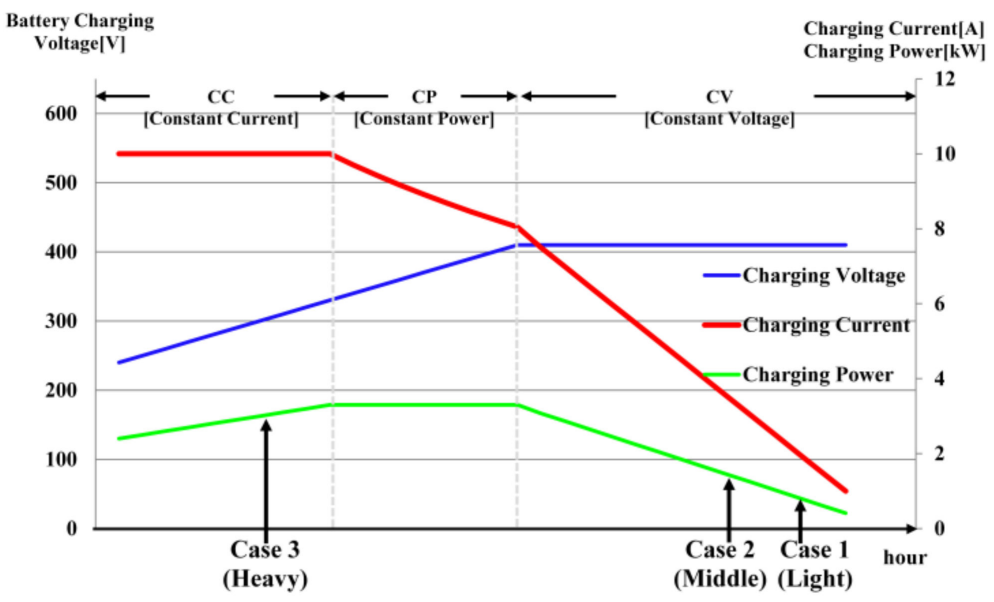

Figure 10. Battery charging profile.

Table 3. IPT converter cases based on main operating point.

\begin{tabular}{cccc}
\hline Parameter & Case 1 & Case 2 & Case 3 \\
\hline Output Power & $820 \mathrm{~W}$ & $1435 \mathrm{~W}$ & $2800 \mathrm{~W}$ \\
State of Charge & $90 \%$ & $80 \%$ & $50 \%$ \\
\hline
\end{tabular}


Figure 11 shows the theoretical losses of the transmitter and receiver system for each case at each main operating point; the $U_{\text {out,opt }}$ values are $130 \mathrm{~V}, 170 \mathrm{~V}$, and $220 \mathrm{~V}$ for Case 1, Case 2, and Case 3, respectively. Depending on the main operating point, the loss fluctuation of the transmitter system is small; in contrast, that of the receiver system is considerable. Consequently, as the output power of the main operating point increases, $U_{\text {out,opt }}$ increases to reduce the loss of the receiver system. Figure $11 \mathrm{~d}$ shows the expected efficiency of the IPT converter based on the loss analysis of each case according to $P_{\text {out }}$ : the maximum efficiency values of Case 1 , Case 2 , and Case 3 are $93.4 \%$ at $820 \mathrm{~W}$, $93.5 \%$ at $1435 \mathrm{~W}$, and $93.7 \%$ at $2800 \mathrm{~W}$, respectively. Figure 12 shows the core loss density distributions of the transmitter and receiver pads in each case at the rated output power, as simulated by the JMAG finite element method. For the transmitter pad, the core loss of Case 1 is the smallest because $U_{\text {out,opt }}$ is the lowest among the cases. In contrast, the core loss of Case 3 is the largest because $U_{\text {out,opt }}$ is the highest among the cases. For the receiver pad, the core loss of Case 1 is the largest, where $U_{\text {out,opt }}$ is the lowest among cases. In contrast, the core loss of Case 3 is the smallest, where $U_{\text {out,opt }}$ is the highest among cases.

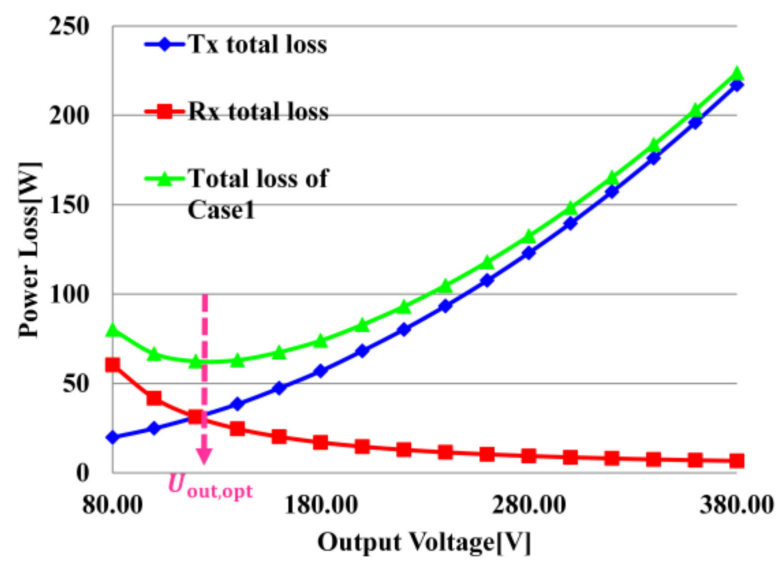

(a)

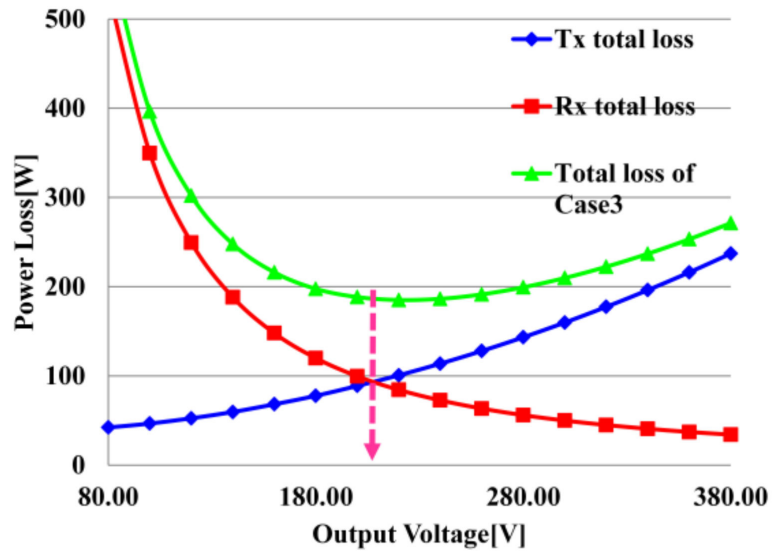

(c)

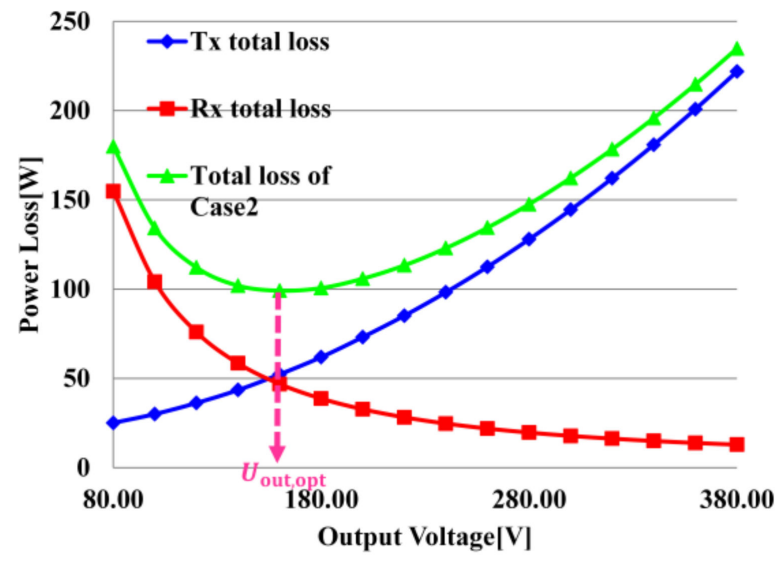

(b)

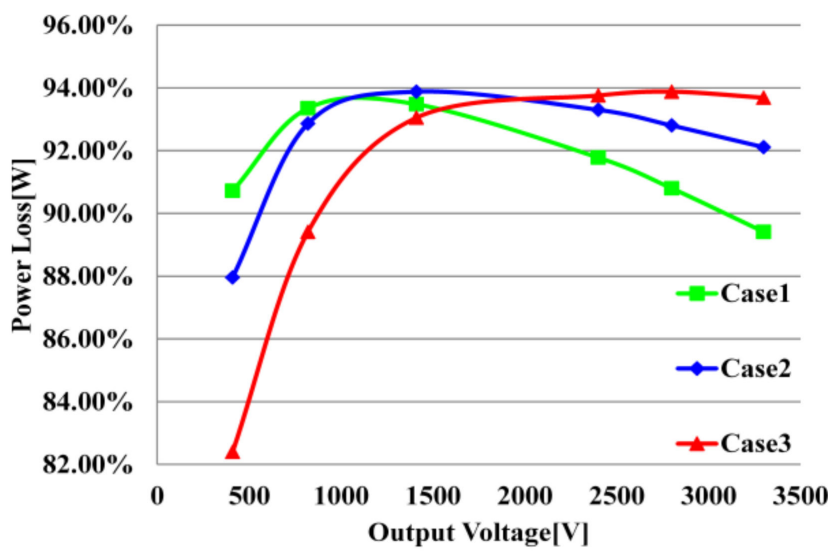

(d)

Figure 11. Loss and efficiency of IPT converter according to cases and output power; (a) Case 1 (b) Case 3 (c) Case 3 (d) expected efficiency of the IPT converter. 

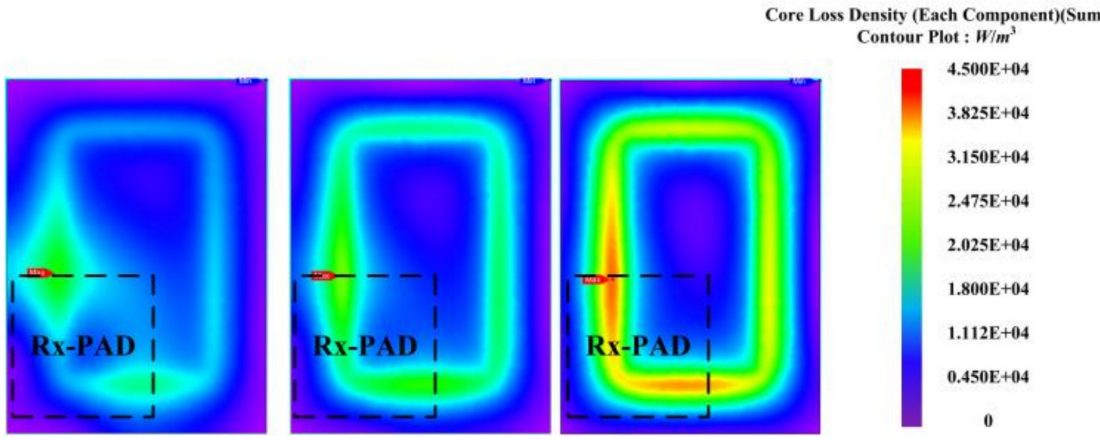

(a)

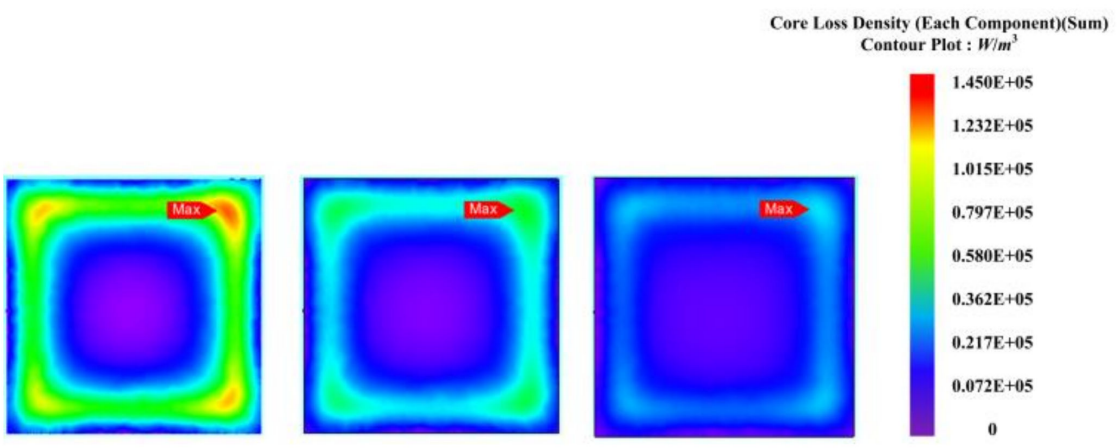

(b)

Figure 12. Core loss density distribution of (a) transmitter pad, (b) receiver pad.

Additionally, the core loss of the transmitter pad is higher than that of the receiver pad because of the pad volume in all cases. However, the core loss density $\left(\mathrm{W} / \mathrm{m}^{3}\right)$ of the receiver pad might be higher than that of the transmitter pad in all cases. Consequently, when $U_{\text {out,opt }}$ is designed by the compensation parameter, the thermal characteristics of the transmitter and the receiver pads should be considered at the rated $P_{\text {out }}$ in addition to the efficiency of the IPT converter.

The BM converter is designed as per the variation range of $U_{\text {out }}$ and $U_{\text {Batt }}$ based on $k$ and SOC. For Case $1, U_{\text {Batt }}$ exceeds $U_{\text {out }}$ throughout the entire ranges of $k$ and SOC; hence, a two-phase interleaved boost converter can be used as the BM converter. For Case 2 and Case 3, by using a two-phase interleaved cascaded buck-boost converter, the BM converter is designed to enable the step-up and step-down as per the battery charging profile of Figure 10. Table 4 shows the $U_{\text {out,opt }}, \mathrm{BM}$ converter, and compensation parameters for each case.

Table 4. Optimal output voltage of IPT converter according to case.

\begin{tabular}{cccc}
\hline Parameter & Case 1 & Case 2 & Case 3 \\
\hline$U_{\text {out,opt }}$ & $130 \mathrm{~V}$ & $170 \mathrm{~V}$ & $220 \mathrm{~V}$ \\
$\mathrm{BM}$ & Boost & Buck-Boost & Buck-Boost \\
Converter & Converter & Converter & Converter \\
& $L_{\mathrm{in}}=58 \mu \mathrm{H}$ & $L_{\mathrm{in}}=44 \mu \mathrm{H}$ & $L_{\mathrm{in}}=34 \mu \mathrm{H}$ \\
Compensation & $C_{\mathrm{p}}=59 \mathrm{nF}$ & $C_{\mathrm{p}}=77 \mathrm{nF}$ & $C_{\mathrm{p}}=100 \mathrm{nF}$ \\
Parameters & $C_{\mathrm{f}}=22 \mathrm{nF}$ & $C_{\mathrm{f}}=20 \mathrm{nF}$ & $C_{\mathrm{f}}=19 \mathrm{nF}$ \\
& $C_{\mathrm{s}}=14 \mathrm{nF}$ & $C_{\mathrm{s}}=14 \mathrm{nF}$ & $C_{\mathrm{s}}=14 \mathrm{nF}$ \\
\hline
\end{tabular}

\section{Experiment Verification}

To verify the proposed design methodology, the $3.3-\mathrm{kW}$ experimental setup of the IPT converter and the $\mathrm{BM}$ converter is configured. The PFC converter can be neglected because the $U_{\mathrm{DC} \text {-Link }}$ of all three cases is $380 \mathrm{~V}$. The electrical specification of the system is consistent 
with the parameter listed in Table 1. The magnetic pads are manufactured in reference to SAE J2954 as shown in Figure 13. The litz wires (primary coil: AWG 9, secondary coil: AWG 12) are utilized to reduce skin and proximity effects. Both the transmitter and receiver pads are composed of PC 95 ferrite. The parameters and dimensions of the LCT are consistent with those listed in Table 2. Four MOSFETs (C3M0030090K) and four Schottky diodes (IDW20G120C5B) are selected to construct the FBI and rectifier. MOSFETs (IDW40G65C5), Schottky diodes (C5D50065D), and inductors are selected to construct the BM converter for each case. A DSP TMS320F28335 is used to control the IPT converter and BM converter. To construct the LCC-S compensation topology, a ferrite core PC95PQ30/25-Z is utilized to build $L_{\text {in }}$ in all cases, and the PCB type compensation capacitor tank is made of a seriesparallel connection of SMD chip ceramic capacitors (C1812C222JDGAC7800). The practical parameters are listed in Table 5; the deviation between the actual and designed parameters is less than $1 \%$. Additionally, the conventional IPT converter is designed in order to compare the conventional and proposed design methodology [25].

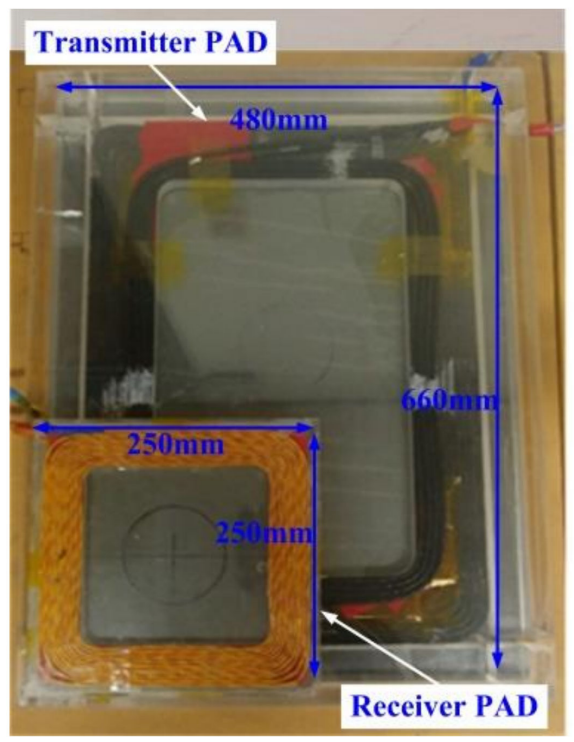

Figure 13. Transmitting and receiving coils and pads.

Table 5. Actual parameters of LCC-S compensation topology.

\begin{tabular}{ccccc}
\hline Parameter & Case 1 & Case 2 & Case 3 & Conventional \\
\hline & $L_{\mathrm{in}}=56.5 \mu \mathrm{H}$ & $L_{\mathrm{in}}=43.2 \mu \mathrm{H}$ & $L_{\mathrm{in}}=33.8 \mu \mathrm{H}$ & $L_{\mathrm{in}}=30.2 \mu \mathrm{H}$ \\
Compensation & $C_{\mathrm{p}}=57.2 \mathrm{nF}$ & $C_{\mathrm{p}}=76.4 \mathrm{nF}$ & $C_{\mathrm{p}}=100 \mathrm{nF}$ & $C_{\mathrm{p}}=114 \mathrm{nF}$ \\
Parameters & $C_{\mathrm{f}}=22.1 \mathrm{nF}$ & $C_{\mathrm{f}}=20.2 \mathrm{nF}$ & $C_{\mathrm{f}}=19.5 \mathrm{nF}$ & $C_{\mathrm{f}}=18 \mathrm{nF}$ \\
& $C_{\mathrm{s}}=14.5 \mathrm{nF}$ & $C_{\mathrm{s}}=14.5 \mathrm{nF}$ & $C_{\mathrm{s}}=14.5 \mathrm{nF}$ & $C_{\mathrm{s}}=14 \mathrm{nF}$ \\
\hline
\end{tabular}

Figure 14 shows the waveforms of $\boldsymbol{U}_{\mathrm{AB}}, \boldsymbol{I}_{\mathrm{in}}, \boldsymbol{U}_{\mathrm{out}}$, and $I_{\mathrm{out}}$ at the main operating point of each case for $k=0.08 ; U_{\mathrm{AB}}$ is constant, and zero voltage switching (ZVS) is implemented for the entire load in all cases. Figure 15 shows the waveforms of $U_{\text {out }}, I_{\text {out }}, U_{\text {Batt }}$, and $I_{\text {Batt }}$ at the main operating point of each case for $k=0.08$. In Case 1 and Case 2, the $U_{\text {Batt }}$ values are $410 \mathrm{~V}$ as a boost mode at $820 \mathrm{~W}$ and $1435 \mathrm{~W}$, which are the main operating points, respectively. In Case 3, the $U_{\text {Batt }}$ values are $280 \mathrm{~V}$ as a boost mode at $2800 \mathrm{~W}$, which is the main operating point. The overall system efficiency $\eta_{\mathrm{DC}}$ of the IPT and BM converters for each case is measured via a power analyzer (HIOKI PW6011) according to the battery charging profile of Figure 10. Maximum $\eta_{\mathrm{DC}}$ for Case 1, Case 2, and Case 3 is $90.6 \%$ at $820 \mathrm{~W} P_{\text {out }}, 91.9 \%$ at $1435 \mathrm{~W} P_{\text {out }}$, and $92.9 \%$ at $2800 \mathrm{~W} P_{\text {out }}$, respectively, as shown in Figure 16. Figure 17 shows the theoretical loss of the IPT converter calculated based on the loss analysis and the experimental loss of the IPT converter measured according to $P_{\text {out }}$; 
the theoretical and experimental losses are considerably similar. Furthermore, Figure $17 \mathrm{~d}$ shows the experimental efficiency of the IPT converter for $k=0.08$. The maximum efficiency values of the IPT converter for Case 1, Case 2, and Case 3 are $93.5 \%$ at $820 \mathrm{~W}, 93.7 \%$ at $1435 \mathrm{~W}$, and $93.8 \%$ at $2800 \mathrm{~W}$, respectively. The maximum efficiency values of the conventional IPT converter is $93.4 \%$ at $3300 \mathrm{~W}$. As a result of experiment, it is verified that the maximum efficiency point of the IPT converter can be selected by the proposed design methodology, unlike the conventional design methodology. The deviation between the experimental and expected efficiency of the IPT converter for each case is less than $1 \%$.

Figure 18 shows the component loss distribution in the IPT converter for each case based on $P_{\text {out }}$. In the transmitter system of the IPT converter, the losses of Case 1 and Case 3 are the smallest and largest among all the cases, respectively. In the receiver system of the IPT converter, the losses of Case 1 and Case 3 are the largest and smallest among all the cases, respectively. In addition, the loss in the transmitter system for all cases barely fluctuates depending on $P_{\text {out }}$, whereas the loss in the receiver system for all cases fluctuates significantly.

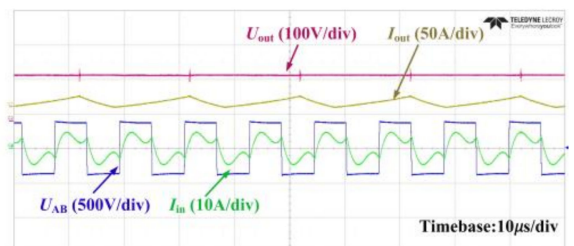

(a)

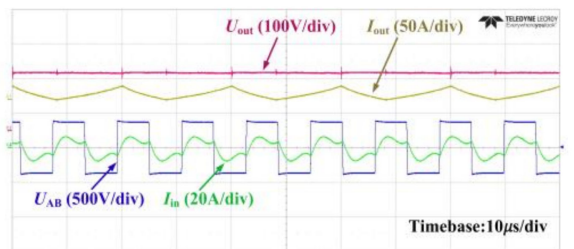

(b)

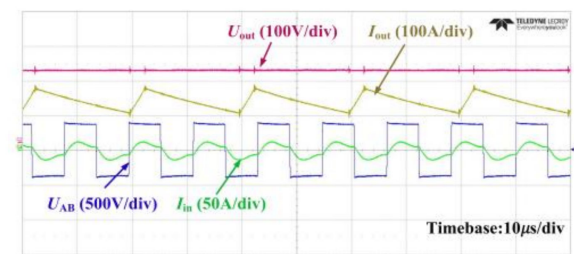

(c)

Figure 14. Waveforms of $\boldsymbol{U}_{\mathrm{AB}}, \boldsymbol{I}_{\mathrm{in}}, U_{\mathrm{out}}$, and $I_{\mathrm{out}} ;$ (a) Case 1, (b) Case 2, (c) Case 3 at main operating point of each case.

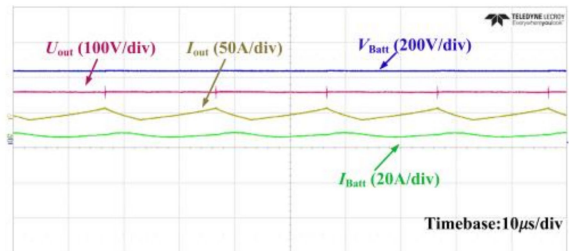

(a)

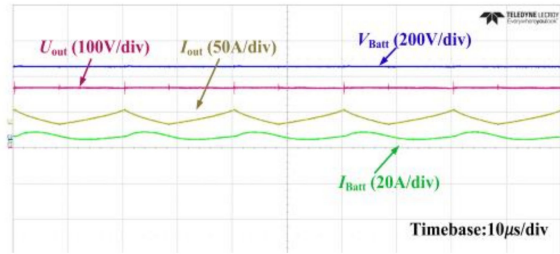

(b)

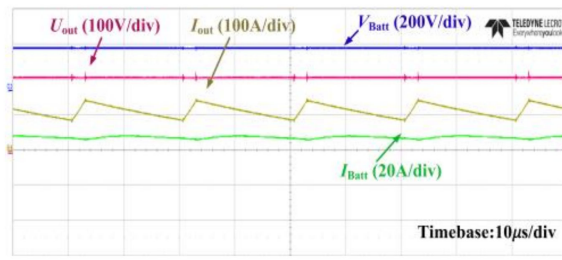

(c)

Figure 15. Waveforms of $U_{\text {out }}, I_{\text {out }}, U_{\text {Batt }}$, and $I_{\text {Batt }}$; (a) Case 1, (b) Case 2, (c) Case 3 at main operating point of each case.

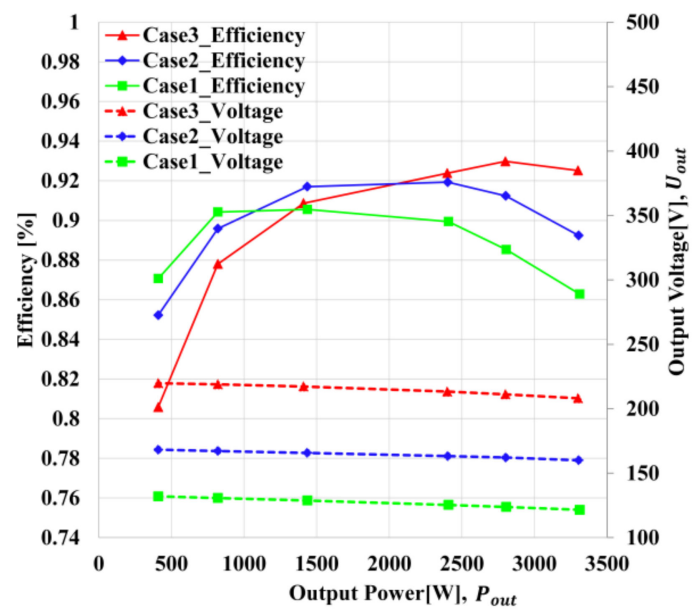

Figure 16. Measured overall system efficiency and $U_{\text {out }}$ according to cases in $k=0.08$. 


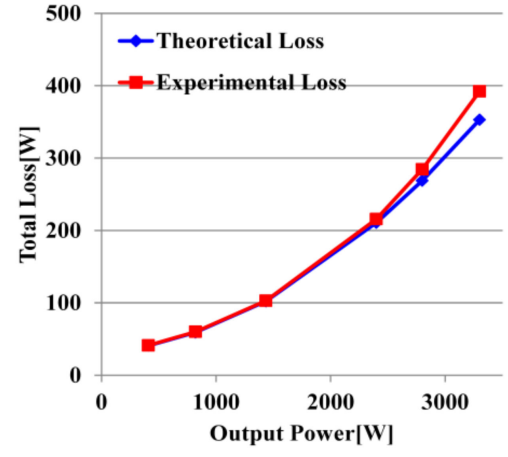

(a)

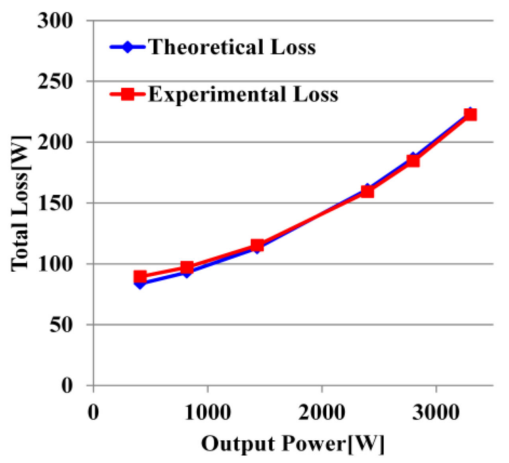

(c)

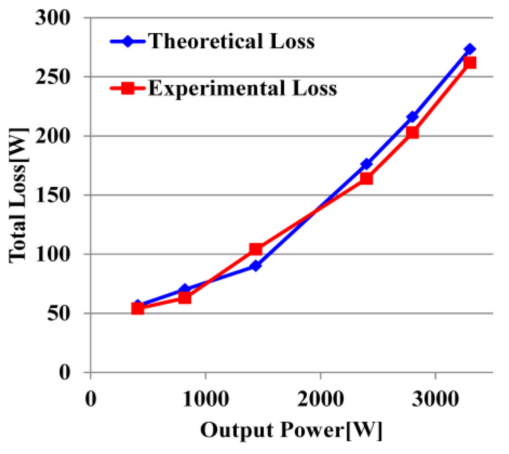

(b)

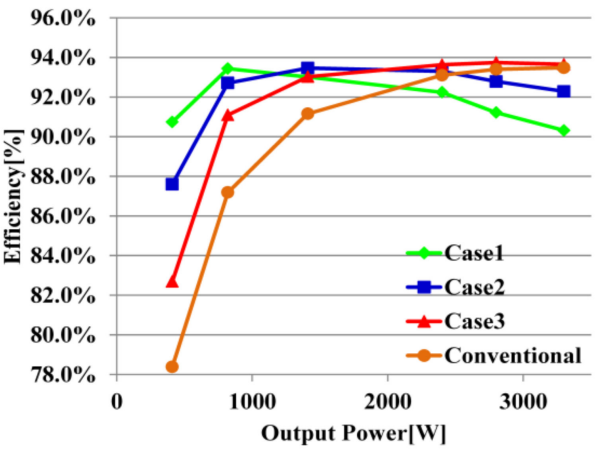

(d)

Figure 17. Theoretical loss and experimental loss of IPT converter according to $P_{\text {out }}$; (a) Case 1, (b) Case 2, (c) Case 3, (d) experimental efficiency of the IPT converter.

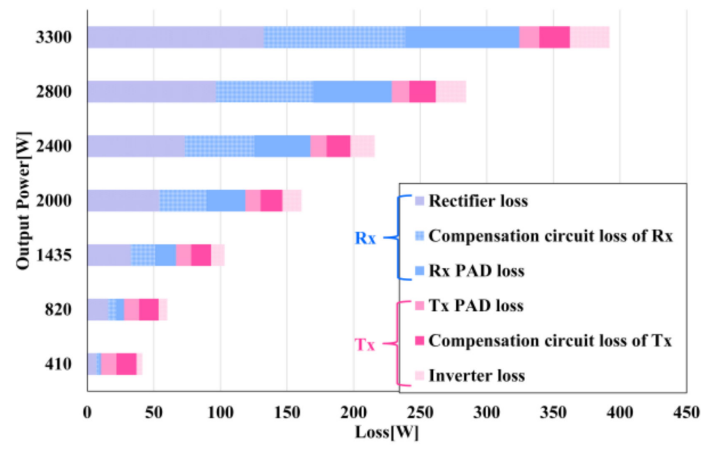

(a)

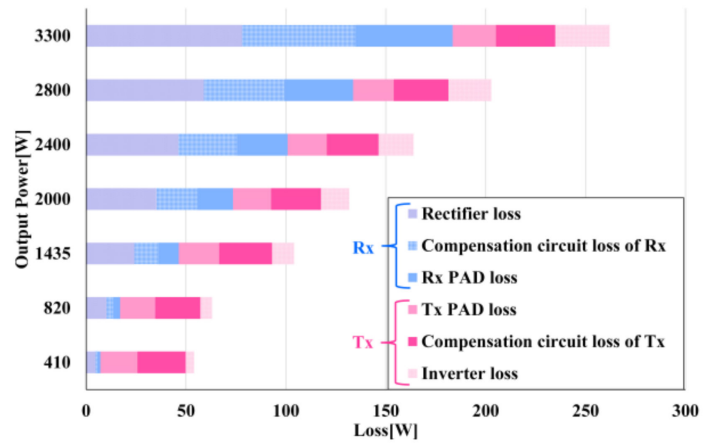

(b)

Figure 18. Cont. 


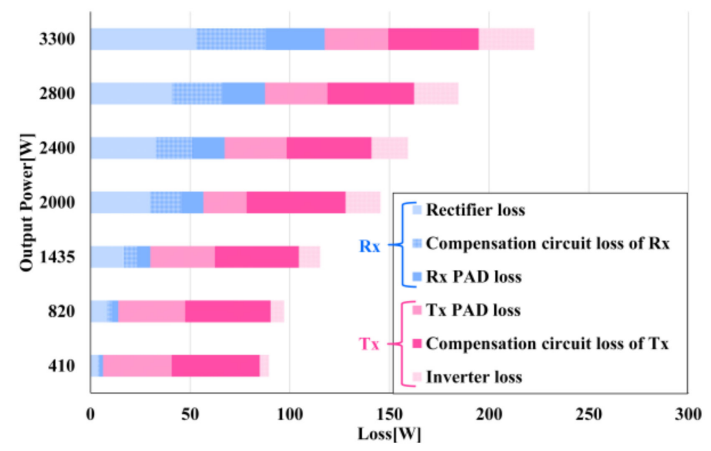

(c)

Figure 18. Loss distribution charts of the IPT converter; (a) Case 1, (b) Case 2, (c) Case 3 according to $P_{\text {out }}$ in $k=0.08$.

\section{Conclusions}

This paper proposes an optimal design methodology on the compensation parameters of the IPT converter for EVs. The losses of the IPT converter are analyzed and compared based on $U_{\text {out }}$. It is confirmed that the loss relationship between the transmitter and the receiver system in the IPT converter shows a trade-off according to $U_{\text {out }}$. The IPT converter is designed for $U_{\text {out,opt }}$ where the losses of the transmitter and the receiver system are the same. The BM converter is designed in consideration of the output voltage of the IPT converter, the fluctuation range of coupling coefficient, and the battery charging voltage. The cases with $3.3 \mathrm{~kW}$ rated output power are classified into three cases based on the main operating point to verify proposed methodology. As a result of experiment, although the efficiency of the IPT converter for each case fluctuates according to the battery equivalent load, the maximum efficiency values for each case are $93.5 \%, 93.7 \%$, and $93.8 \%$ at each main operating point, respectively. The proposed design methodology provides high design freedom for the IPT converter to select the maximum efficiency point, unlike the conventional design methodology. Owing to these advantages, the proposed design methodology is expected to be used not only for EVs but also for WPT applications such as automated guided vehicles and unmanned aerial vehicles.

Author Contributions: Conceptualization, C.-H.J.; funding acquisition, D.-H.K. All authors have read and agreed to the published version of the manuscript.

Funding: This research was supported by the National Research Foundation of Korea (NRF) grant funded by the Korea government (MSIT) (No. NRF- 2020R1I1A3073169).

Institutional Review Board Statement: Not applicable.

Informed Consent Statement: Not applicable.

Data Availability Statement: Not applicable.

Conflicts of Interest: The authors declare no conflict of interest.

\section{References}

1. Moon, S.; Moon, G. Wireless Power Transfer System with an Asymmetric Four-Coil Resonator for Electric Vehicle Battery Chargers. IEEE Trans. Power Electron. 2016, 31, 6844-6854.

2. Miller, J.M.; Jones, P.T.; Li, J.-M.; Onar, O.C. ORNL experience and challenges facing dynamic wireless power charging of EV's. IEEE Power Electron. Mag. 2015, 15, 40-53. [CrossRef]

3. Chen, Y.; Zhang, H.; Park, S.; Kim, D. A switching hybrid LCC-S compensation topology for constant current/voltage EV wireless charging. IEEE Access. 2019, 7, 133924-133935. [CrossRef]

4. Zakerian, A.; Vaez-Zadeh, S.; Babaki, A. A Dynamic WPT System with High Efficiency and High Power Factor for Electric Vehicles. IEEE Trans. Power Electron. 2020, 35, 6732-6740. [CrossRef]

5. Li, S.; Mi, C. Wireless power transfer for electric vehicle applications. IEEE J. Emerg. Sel. Topics Power Electron. $2015,3,4-17$.

6. Li, W.; Zhao, H.; Deng, J.; Li, S.; Mi, C. Comparison study on SS and double-sided LCC compensation topologies for EV/PHEV wireless chargers. IEEE Trans. Veh. Technol. 2016, 65, 4429-4439. [CrossRef] 
7. Zhang, W.; White, J.C.; Malhan, R.K.; Mi, C.C. Loosely coupled transformer coil design to minimize EMF radiation in concerned areas. IEEE Trans. Veh. Technol. 2016, 65, 4779-4789. [CrossRef]

8. Budhia, M.; Covic, G.A.; Boys, J.T. Design and optimization of circular magnetic structures for lumped inductive power transfer systems. IEEE Trans. Power Electron. 2011, 26, 3096-3108. [CrossRef]

9. Chen, Y.; Zhang, H.; Shin, C.; Seo, K.; Park, S.; Kim, D. A Comparative Study of S-S and LCC-S Compensation Topology of Inductive Power Transfer Systems for EV Chargers. In Proceedings of the 2019 IEEE 10th International Symposium on Power Electronics for Distributed Generation Systems (PEDG), Xi'an, China, 3-6 June 2019.

10. Ann, S.; Lee, B.K. Analysis of Impedance Tuning Control and Synchronous Switching Technique for a Semibridgeless Active Rectifier in Inductive Power Transfer Systems for Electric Vehicles. IEEE Trans. Power Electron. 2021, 36, 8786-8798. [CrossRef]

11. Chen, Y.; Zhang, H.; Shin, C.; Jo, C.; Park, S.; Kim, D. An Efficiency Optimization-Based Asymmetric Tuning Method of Double-Sided LCC Compensated WPT System for Electric Vehicles. IEEE Trans. Power Electron. 2020, 35, 11475-11487. [CrossRef]

12. Wang, C.-S.; Covic, G.A.; Stielau, O.H. Power transfer capability and bifurcation phenomena of loosely coupled inductive power transfer systems. IEEE Trans. Ind. Electron. 2004, 51, 148-157. [CrossRef]

13. Fu, M.; Yin, H.; Zhu, X.; Ma, C. Analysis and Tracking of Optimal Load in Wireless Power Transfer Systems. IEEE Trans. Power Electron. 2015, 30, 3952-3963. [CrossRef]

14. Li, H.; Li, J.; Wang, K.; Chen, W.; Yang, X. A Maximum Efficiency Point Tracking Control Scheme for Wireless Power Transfer Systems Using Magnetic Resonant Coupling. IEEE Trans. Power Electron. 2015, 30, 3998-4008. [CrossRef]

15. SAE. Wireless Power Transfer for Light-Duty Plug-In and Electric Vehicles and Alignment Methodology J2954; SAE Standard: Warrendale, PA, USA, 2016.

16. Hou, J.; Chen, Q.; Zhang, Z.; Wong, S.-C.; Tse, C.K. Analysis of output current characteristics for higher order primary compensation in inductive power transfer systems. IEEE Trans. Power Electron. 2018, 33, 6807-6821. [CrossRef]

17. Lu, J.; Zhu, G.; Wang, H.; Lu, F.; Jiang, J.; Mi, C.C. Sensitivity analysis of inductive power transfer systems With voltage-fed compensation topologies. IEEE Trans. Veh. Technol. 2019, 68, 4502-4513. [CrossRef]

18. Zhang, W.; Mi, C.C. Compensation Topologies of High-Power Wireless Power Transfer Systems. IEEE Trans. Veh. Technol. 2016, 65, 4768-4778. [CrossRef]

19. Li, S.; Li, W.; Deng, J.; Nguyen, T.D.; Mi, C. A double-sided LCC compensation network and its tuning method for wireless power transfer. IEEE Trans. Veh. Technol. 2015, 64, 2261-2273. [CrossRef]

20. Ramezani, A.; Farhangi, S.; Iman-Eini, H.; Farhangi, B.; Rahimi, R.; Moradi, G.R. Optimized LCC-Series Compensated Resonant Network for Stationary Wireless EV Chargers. IEEE Trans. Ind. Electron. 2019, 66, 2756-2765. [CrossRef]

21. He, H.; Wang, S.; Liu, Y.; Jiang, C.; Wu, X.; Wei, B.; Jiang, B. Maximum Efficiency Tracking for Dynamic WPT System Based on Optimal Input Voltage Matching. IEEE Access. 2020, 8, 215224-215234. [CrossRef]

22. Vu, V.B.; Tran, D.H.; Choi, W. Implementation of the constant current and constant voltage charge of inductive power transfer systems with the double-sided LCC compensation topology for electric vehicle battery charge applications. IEEE Trans. Power Electron. 2018, 33, 7398-7410. [CrossRef]

23. Kim, M.; Joo, D.M.; Woo, D.-G.; Lee, B.K. Design and control of inductive power transfer system for electric vehicles considering wide variation of output voltage and coupling coefficient. In Proceedings of the IEEE Conference on Applied Power Electronics Conference and Exposition (APEC), Tampa, FL, USA, 26-30 March 2017; pp. 3648-3653.

24. Byeun, J.-E. Design and Control Strategy of Wireless Power Transfer Charging System with Bridgeless Rectifier for Electric Vehicles. Ph.D. Thesis, Dept. Elect. Eng., Sungkyunkwan University, Suwon, Korea, 2020.

25. Kim, M.; Joo, D.; Lee, B.K. Design and Control of Inductive Power Transfer System for Electric Vehicles Considering Wide Variation of Output Voltage and Coupling Coefficient. IEEE Trans. Power Electron. 2019, 34, 1197-1208. [CrossRef]

26. Feng, H.; Cai, T.; Duan, S.; Zhao, J.; Zhang, X.; Chen, C. An LCC-Compensated Resonant Converter Optimized for Robust Reaction to Large Coupling Variation in Dynamic Wireless Power Transfer. IEEE Trans. Ind. Electron. 2016, 63, 6591-6601. [CrossRef]

27. Mühlethaler, J. Modeling and Multi-Objective Optimization of Inductive Power Components. Ph.D. Thesis, Dept. Elect. ENg., ETHZ, Zürich, Switzerland, 2012. 